\title{
Iranian Parents' Resistance to Incompatible Aspects of Western Culture: Implications for ELT Material Development
}

\author{
Seyed Ahmad Kasaian (corresponding author) \\ $\mathrm{PhD}$ Candidate in Applied Linguistics, University of Mysore, India \\ PO box57007- \#1365- $3^{\text {rd }}$ main $-2^{\text {nd }}$ stage - Vijayanagar - Mysore - India. \\ Tel: 91- 998-659-0749 E-mail: Ahmadkasa_amir@yahoo.com
}

Rangaswamy Subbakrishna

Reader cum Research Officer, Central Institute of Indian Languages (CIIL), Mysore, India

PO box 570006 - Central Institute of Indian Language (CIIL), Hunsur Road, Manasagangothri, Mysore, India.

$$
\text { Tel: 91-944-850-4664 E-mail: rsubbakrishna@gmail.com }
$$

\begin{abstract}
The British and US varieties of English have now come under suspicion of promoting American and British ways of life and marginalizing the local identities of their learners. Prompted by these suspicions, many scholars and policy makers have voiced doubts about the cultural adequacy of the native speaker-controlled ELT programs. In a recent survey conducted by the present authors (forthcoming), the attitude of the Iranian education officials towards the teaching of English in its western cultural context was surveyed. The findings indicated that they strongly disapproved of the teaching of English along with its western cultural values. To find out whether the above official resistance in Iran has the backing of the general public, a cultural resistance survey was conducted. 393 male and female Iranian parents from different walks of life participated in this survey. The results showed that the high school students' possible adoption of the western lifestyle and their exposure to the manifestations of incompatible western culture were resisted by their parents. Based on the findings of this research, the researchers made a number of recommendations for international, regional and local ELT material development.
\end{abstract}

Key words: Iranian parents' cultural resistance, ELT material development, Regional ELT material development, Language and culture, Iranian local EFL curriculum

\section{Introduction}

Whereas some decades ago "the target for learning was assumed to be a native-speaker variety of English and it was the native speaker's culture, perceptions, and speech that were crucial in setting goals for English teaching" (Richards, 2003, p.17), and for that reason "it was the figure of the native speaker that invariably served as the yardstick with which to measure the adequacy of policy decisions, the efficacy of methods and authenticity of materials, the learner's proficiency, and so on" (Rajagopalan, 2004, p.114), now there is a growing tendency in many parts of the world to dissociate the ELT profession from the native speakers' norms of linguistic accuracy and social appropriateness (Shafi, 1993; Hyde,1994; Kubota, 1998). The reasons for this paradigm shift are numerous. Outstanding among them is the reason that the wholehearted enthusiasm and the unfailing trust with which the authority of the native speakers used to be embraced have given way to distrust and suspicions about the imperialistic motives behind the teaching of the Standard English: "To continue promoting Standard English as an Anglo-American commodity can be linked to supporting an Anglo-Americanization that can potentially eradicate social, cultural, and linguistic diversity locally as well as globally (Modiano, 2009, p.220) . Therefore, the teaching of the British and US varieties of English which set the native speakers' communicative competence as a goal is presently facing adamant resistance on the part of the learners, critical applied linguists, policy makers, world governments and students' parents in many EFL/ESL contexts.

\subsection{Statement of the problem}

The results of a survey of the Iranian education officials' attitudes by the present authors (forthcoming) showed that they had apprehension about and resisted the possible unwanted cultural influences of English on the Iranian high school students. The present survey aims to probe into the nature of the Iranian high school students' parents' attitude towards their children's exposure to and their possible adoption of a western lifestyle to see whether the 
observed official resistance in Iran has the backing of the general public or not. The results of this survey can have clear implications for ELT curriculum development at the global, regional and local levels.

\subsection{Research Questions and hypotheses}

To survey the Iranian parents' attitudes towards their children's exposure to the incompatible aspects of the western culture and their possible adoption of a western lifestyle, one major and four minor research questions were posed and their corresponding null hypothesis and sub-hypotheses were formulated. In view of the limitations of space only the hypotheses are included here.

The main null hypothesis: The Iranian high school students' parents do not show resistance to their children's adoption of the western lifestyle and their exposure to the incompatible aspects of western culture.

To see whether, age, education, monthly income and gender influenced the nature of the respondents' attitude towards the issue under investigation, the following four sub-hypotheses were formulated.

The first sub-hypothesis: Monthly income does not influence the Iranian high school students' parents' attitudes towards their children's exposure to the incompatible aspects of western culture and their possible adoption of the western lifestyle.

The second sub-hypothesis: Education level does not influence the Iranian high school students' parents' attitudes towards their children's exposure to the incompatible aspects of western culture and their possible adoption of the western lifestyle.

The third sub-hypothesis: Age does not influence the Iranian high school students' parents' attitude towards their children's exposure to the incompatible aspects of western culture and their possible adoption of the western lifestyle.

The fourth sub-hypothesis: Gender does not influence the Iranian high school students' parents' attitude towards their children's exposure to the incompatible aspects of western culture and their possible adoption of the western lifestyle.

\section{Theoretical Background}

\subsection{Suspicions about the imperialistic motives behind the teaching of English in its western cultural context}

English was formerly thought to be a neutral and saintly language and "the vehicle for the expression of a rich and advanced culture, or cultures, whose literary artifacts had universal values" (Richards, 2008, p. 3). But now many ELT experts and educators overtly display pessimism about the role English is playing in the world and see it as a vehicle used by some powerful countries in the world to transfer their thoughts, ideologies and social attitudes to the other nations of the world who have to learn English."Among foreign languages, English serves as a highway along which not only neutral messages but also thought, ideology, and social attitudes are transferred. English thus serves as a vehicle of what Phillipson (1992) called linguistic imperialism." (Neustupný and Nekvapil, 2003, pp.155-6) Cooke's (1988) 'Trojan Horse' metaphor is a clear indication of this pessimism and suspicion about the initial harmless-looking arrival of English in many countries with its perceived hidden long-term detrimental influences on the linguistic and cultural identities of its host communities. If "L2 learners develop the ability to use the target language in appropriate ways for the specific purpose of culturally empathizing, if not culturally assimilating, with the native speakers of English [...] the individual voice and the cultural identity of the L2 learner stand hopelessly marginalized" (Kumaravadivelu, 2003,p.543).

\subsection{Retaliatory resistance through teaching English out of its western culture}

In response to the perceived hegemony of English, many nations began to think of safeguarding their languages and local cultures in the face of the dominant language and culture of what Kachru (1985) termed the 'inner circle countries'. "Retaining our indigenous cultures and language(s) while reaping the benefits of large-scale integration via a language of wider communication is the challenge many of us will no doubt have to come to terms with in the years to come" (Modiano, 2004, p. 225). One suggestion to avert the consequences of teaching English has been to use it "as a purely instrumental tool, nothing more than a linguistic means to certain ends" (Hyde, 1994,p.296) so that "the culture behind the language can be 'contained', and the unwanted side-effects of English language learning reduced". (ibid)

Randal Holme's (2003) "the instrumental or culture-free-language view" is a description of one possible strategy to hold back the flow of western culture into learners' local communities through the ELT program:

This view could proceed from a common concern in respect of the hidden political and cultural agenda of a language. Phillipson's (1992) thesis argues that a dominant language such as English is owned by the 
socioeconomic centre of global power that comprises the BANA (British, Australasian and North American) countries. The language emanates out from this 'centre' towards 'the periphery' as a mechanism of cultural and epistemological impoverishment for those located there (Phillipson, 1992: 52). Implicit in this argument is the view that a language will become a mechanism of cultural transmission, promoting the values of its host-culture against those of the regions to which it is exported. (p. 19)

He further mentioned that many counties have come to "possess a strong awareness of the dangers of cultural contamination implicit in the learning of a dominant international language" (ibid) and have decided "to contextualise the target language in the students' own region and culture" (ibid) to hold back its unwanted cultural influences.

\section{Method}

\subsection{Research design}

This study had a survey design as it aimed at surveying the attitudes of the Iranian high school students' parents towards the incompatible western cultural values and their children's possible adoption of the western lifestyle.

\subsection{Instrumentation}

The instrument used in this survey was a cultural resistance questionnaire which was developed and validated by the present researchers. A 14-item Likert-scale questionnaire which had survived the expert review for it content validity was administered to 130 male and female parents of Iranian high school students to test its construct validity. The collected questionnaire data in the pilot phase was subjected to Principal Component Analysis (PCA) with varimax rotation to ensure the construct validity of the questionnaire and to extract the latent components. The minimum acceptable loading for each item was set at $+/-0.50$. Three components were extracted with the total variance of 65.647. Item 13 was omitted as a result of running PCA and the validated questionnaire comprised 13 items. The questionnaire started with a brief introduction that explained the nature and purpose of the study to the respondents and gave them the necessary assurance about the anonymity of their responses. The last section of the questionnaire included a number of general demographic questions. (Appendix A contains the English translation of the questionnaire)

\subsection{Sampling}

The method of sampling in this research was stratified random sampling as the whole population of respondents was divided into some 'strata' from which a proportionate size was randomly selected. The eligible respondents were stratified based on such factors as gender, education, age and income.

\subsection{Participants}

600 questionnaires were distributed among the same number of Iranian high school students' parents. 393 parents returned their completed questionnaires and constituted the participants of this survey. The respondents fell into three age groups. About $30 \%$ of the respondents were in their $30 \mathrm{~s}, 55.5 \%$ of them were in their $40 \mathrm{~s}$ and $14.5 \%$ of the participants were in their 50s. As for the respondents' level of education, the respondents were divided into three groups: 1) those whose education was up to high school diploma, 2) those with associated diplomas and bachelor's degrees, and 3) those who held master's or PhD degrees. Also of interest to this study was the respondents' monthly income. Therefore, they were put into three categories based on their monthly income level and were compared for the possible differences in their attitudes.

\subsection{Procedure}

\subsubsection{Data collection}

The researchers started the collection of the data from the students' parents by personally distributing the questionnaires to some potential respondents in Sari, Qaemshahr, Babol, Firouzkouh and Tehran cities. To involve respondents from a larger number of cities in Iran, they sent the questionnaires to some friends and colleagues in Guilan, Mazandaran, Tehran, Khoozestan, Sistan Baluchestan, Kurdestan, Khorasan Razavi, Semnan, Eastern Azerbaijan and Qazvin provinces who administered the questionnaires to both mothers and fathers of the Iranian high school students from different walks of life and different socioeconomic backgrounds. A total of 600 questionnaires were distributed among the potential respondents in the cities mentioned above out of which 393 completed questionnaires were collected.

\subsubsection{Data analysis}

Following the collection of the data from the respondents, every respondent was given a code and his/her responses were given values from 1 to 7 . Then the researchers condensed the 7 choices of each item into 3 more general 
categories. The first category was labeled the 'approval' category and included choices showing the lowest degree of resistance (i.e. choices corresponding to the values of 1,2 and 3). The second category was labeled 'Neutrality' and included the one choice that fell in the middle of the seven choices with the value of 4 . The third category included choices that fell on the higher side of the neutral point (i.e. 5, 6 and7). This category was deemed to be indicative of the parents' resistance to their children's adoption of a western lifestyle or their exposure to the manifestations of the incompatible aspects of the western culture and was accordingly labeled 'Resistance'. The data obtained from the respondents were tabulated and transferred to SPSS spreadsheet for descriptive and inferential statistical analyses.

To assess the normality of the data which is the underlying assumption in parametric testing, both the numerical method of the Kolmogorov-Smirnov Test and the graphic method of normal Q-Q Plot were used. The results of both methods showed that the assumption of the normality of data was not met. Accordingly, the researchers used the non-parametric tests to analyze the data obtained from the survey.

To determine whether the high school students' parents generally resisted their children's adoption of the western lifestyle and/or their exposure to the incompatible aspects of the western culture, the chi square test was applied to the frequencies of responses in the three categories of resistance, neutrality and approval. To scrutinize the respondents' attitude towards different aspects of the issue under consideration both component-by-component and item-by-item analyses were also done. The respondents were, then, grouped based on their age, gender, education and income and their levels of resistance were compared across the groups using the Kruskal Wallis and Mann-Whitney Tests.

\subsubsection{The verification of the null hypothesis}

The null hypothesis: The Iranian high school students' parents do not show resistance to their children's adoption of the western lifestyle and their exposure to the incompatible aspects of the western culture.

To verify the null hypothesis, the data obtained from the whole questionnaire was subjected to the chi-square test. The SPSS output for the chi square test appears in Table 1. More than three-quarters (\%76.18) of the responses fell in the resistance category and the chi square value of 4407.038 was found to be highly significant $(\mathrm{P}=0.000)$. This signified that the respondents showed strong resistance to their children's possible adoption of a western lifestyle and their exposure to the incompatible aspects of the western culture. Therefore, the null hypothesis which assumed no resistance on the part of the respondents was rejected.

The analysis of the results obtained from the questionnaire as a whole confirmed the Iranian high school students' parents' resistance to the issue in question. Although the result was informative, it did not tell us anything about the respondents' attitude towards each aspect of this general resistance. Hence, a component-by-component analysis was done to scrutinize the respondents' attitude towards different aspects of the issue. The results showed that in none of the three components, the responses were equally distributed among the three categories. The first component had five items and measured the nature of the parents' attitudes towards some instances of the western lifestyle. As it is shown in Table 2,78.16\% of the respondents disapproved of their children' adoption of those incompatible aspects of the western life that were described in the questionnaire. The second component included items that measured the respondents' attitude towards parental and governmental supervision and control. $77.39 \%$ of the parents who took the questionnaire showed resistance to the influence of the incompatible aspects of western culture on their children by agreeing with the parental and governmental supervision. Component three was to measure the extent to which the parents were suspicious of a hidden agenda in the imported ELT materials. $67.51 \%$ of the parents showed suspicion about the existence of a hidden agenda in the imported ELT materials.

Both at the whole questionnaire level and at the component level, the survey data collected from the respondents showed their strong resistance to their children's adoption of the described aspects of the western lifestyle and their exposure to the manifestations of the incompatible aspects of the western culture thereby rejecting the null hypothesis. An item-by-item analysis of the respondents' attitude was also justified as it could provide the researchers with a more detailed understanding of the nature of their attitude. With this justification, the researchers applied the chi square test to the three groups of frequencies of responses to determine the contribution of each item to the overall resistance and whether there were items that countered the observed general resistance. In the case of all the thirteen items, the resistance category attracted the bulk of responses which confirmed the contribution of each item to the overall observed resistance.

\subsubsection{The sub-hypotheses of parents' attitude survey}

In view of the heterogeneity of the high school students' parents in terms of gender, age, level of education and monthly income, the respondents' attitude were analyzed by taking into account the above four moderator variables. 


\subsection{The verification of the first sub-hypothesis}

In order to see whether the high school students' parents with different levels of monthly income had the same or different attitudes towards the issue under investigation, the Kruskal Wallis Test, which is the non-parametric equivalent of one-way ANOVA, was used for the analysis of the collected data.

The SPSS output for Kruskal-Wallis test is tabulated in Table 3. The P value of .000 is less than .05 . This means that the difference among the mean ranks of the three groups was statistically significant and income made a difference in the respondents' level of resistance. To test the statistical significance of the observed difference between the groups two by two, the researchers used the Mann-Whitney Test. The result showed that a higher monthly income corresponded with a lower level of resistance! This rejected the first sub-hypothesis.

\subsection{The verification of the second sub-hypothesis}

Prior to the analysis of the data obtained from the parents with different educational backgrounds, the seven categories of respondents' education levels were condensed into the following three categories: 1) Up to high school diploma, 2) Associated diploma and bachelor's degree 3) Master's degree and PhD. Next, the Kruskal-Wallis Test was used to compare the mean rank of the three groups with the result that a higher level of education corresponded to a lower level of resistance. In Table 4, which summarizes the SPSS output, the value of P equals .000 which means the differences among the three groups were highly significant. Observe the details of the SPSS output in the Table 4

To decide whether the difference between each two groups was statistically significant, the Mann-Whitney Test was run. The results of Mann-Whitney test for groups 1 and 3 as well as that for groups 2 and 3 showed that parents with master's and $\mathrm{PhD}$ degrees had lower resistance than the first two groups. This served to reject the second null sub-hypothesis.

\subsection{The verification of the third sub-hypothesis}

The third moderator variable considered in the analysis of the parents' attitude was the respondents' age. The respondents fell into three age groups: Parents in their 30s, 40s, and 50s. The differences among the mean ranks of the three groups were compared using the Kruskal-Wallis Test. The chi square values of 13.436 in columns 5 of Table 5 was found highly significant $(\mathrm{P}=.001)$ confirming the difference among the resistance levels of the three age groups. To further investigate the difference among the three groups, we compared their mean ranks two by two using the Mann-Whitney Test. The results indicated that the parents in their 50s showed less resistance than those in their $30 \mathrm{~s}$ and those in their $40 \mathrm{~s}$. The observed statistically significant differences served to reject the third sub-hypothesis.

\subsection{The verification of the fourth sub-hypothesis}

Gender was the last moderator variable considered in the analysis of parents' attitude survey. The Mann-Whitney Test was run to find out whether mothers and fathers of the high school students taking part in the survey had a similar attitude towards the issue under investigation. The $\mathrm{P}$ value of 0.591 (shown in the last column of Table 6) showed that the observed difference between their mean ranks the two groups was not statistically significant and they had a similar attitude towards the issue. This confirmed the fourth null sub-hypothesis.

\section{Discussions and Conclusions}

The survey of the high school students' parents' cultural attitudes confirmed their resistance to their children's exposure to the manifestations of the incompatible aspects of the western culture and disapproval of their possible adoption of a western lifestyle. The following can be said about the respondents' cultural attitudes.

1).The majority of the surveyed Iranian high school students' parents disapproved their children's participation in parties in which alcoholic drinks are consumed and girls in revealing clothes intermingle with boyfriends (items 1 and 5). They also disapproved their children's having friends from the opposite sex (item 9) and their going to mixed-gender swimming pools (item 10). These are a few examples of activities which are typically western and conflict with the established cultural norms of the Iranian society which are greatly inspired by Islam. These activities are strongly forbidden in Islam and were not, for that reason, acceptable to the Muslim respondents of this survey. The conclusion to be drawn from this observation is that the Iranian parents do not want their children to adopt a lifestyle which is incompatible with the established cultural norms of their society.

2).Not only did the Iranian parents resist their children' adoption of a lifestyle which clashes with their local cultural identity but also they disapproved their exposure to the manifestations of those same incompatible cultural aspects. They thought that their children's repeated exposure to the textual and pictorial description of western-style mixed-gender parties where alcohol is consumed and girls in revealing clothes intermingle or dance with boys could 
negatively influence their ideal upbringing (items 2 and 5) and that they would be concerned if their children's English textbooks contained pictorial and textual description of such concepts as cohabitation and mixed student dorm rooms which are permissible in the west but strongly discouraged by their local culture (item 3 ). They also said that they were particular about the cultural appropriateness of the content of English textbooks their children studied, the instructional movies they watched and the websites they surfed. To show their concern about the cultural appropriateness of the things their children would be exposed to, they said they would block those satellite TV channels that are deemed to have detrimental cultural effects on their children. This concern was reiterated when they said they preferred locally-designed ELT materials to the imported ones because the former would not expose their children to the undesirable cultural contents that the latter may do. To prevent this unwanted exposure from happening, they legitimized parental (item 7) and governmental (items 8 and 11) monitoring. The justification for their inclination was shown to be the thinking that exposure to the undesirable aspects of the western culture can interest them in the incompatible western lifestyle whether this influence comes as a natural outcome of exposure (item 6) or happens as a consequence of planned cultural hegemony (item 12).

Taking the results of this study into account, we can now conclude that the Iranian high school students' parents, who are entitled to comment on the type of education their children receive, think that their children's exposure to the incompatible aspects of the western culture is undesirable because they think that this exposure is detrimental to their ideal upbringing. One possible reaction to the cultural concerns of the Iranian parents is an unexaggerated exclusion of the incompatible aspects of the western culture from the ELT curriculum meant for the Iranian students. A judicious exclusion that does not deprive the curriculum of the necessary compatible cultural elements of language learning and does not hamper the technical adequacy, efficiency and attractiveness of the curriculum can be a response to the concerns of the Iranian parents.

\section{Implications}

\subsection{Implications for EIL material development}

In view of the existence of undeniably serious cultural resistance in many countries of the world and the consequential irrelevance of native speakers' model for the learners of English in those situations, ELT materials which choose to remain persistently committed to the promotion and dissemination of the British and US varieties of English and are for that reason replete with the western cultural values are blacklisted and rejected by the education officials and students' parents in those countries. As clearly demonstrated by the findings of the present research, a case in point is the Islamic Republic of Iran in which the students' parents showed no interest in their children's adoption of a western lifestyle and resisted their exposure to those aspects of the western culture that clashed with their local culture. Accordingly, the teaching of the Standard English which involves the inclusion of large doses of western culture in the ELT materials is resisted so much so that the Iranian high school students' parents said that they preferred the locally designed ELT materials to the imported ones for cultural reasons. The implication of this observation for the development of ELT materials for the international students is that international material developers should take cognizance of this grave concern many world governments, educators and parents have about the incompatibility of the cultural content of internationally marketed ELT materials with their local cultures and be responsive to the differential needs of diverse learners of English at the international level. One possible way of paying heeds to such concerns is to differentiate between materials developed for learners of English as a second language who may have very strong assimilative motivations and choose to learn English as a requirement for their indistinguishable membership in the community of native speakers and materials developed for learners of English as an International Language whose motivation for learning English is at best instrumental. The members of the latter group want to learn English to interact more with other non-native speakers than with native speakers of English and use English as an instrument to introduce their own cultural identity to others. The development of materials for the latter group necessarily involves the consideration and implementation of the principles of English as an International Language (EIL). "EIL in fact rejects the idea of any particular variety being selected as a lingua franca for international communication. EIL emphasizes that English, with its many varieties, is a language of international, and therefore intercultural, communication." (Sharifian, 2009, p.1) The findings of this research corroborates the irrelevance of the native speakers' model emphasized by Mckay (2002 p. 145) who contends that "English is an international language and because of this fact, English can no longer be linked exclusively to native English-speaking cultures. Hence, there is no need, in the teaching of EIL, to base the content of teaching materials [...] on native-speaker models."

\subsection{Implications for local material development}

Whenever internationally-marketed ELT materials are rejected on the grounds that they are culturally, politically or ideologically inappropriate for certain situations and are replaced with locally-developed ones, utmost care must be 
taken to ensure the technical adequacy of the locally designed materials. This is important because cultural safety which is inherently a legitimate concern cannot be achieved if it takes its toll on the technical quality of the curriculum. A technically weak and professionally inadequate curriculum cannot be called a curriculum at all because it fails to serve the main purpose for which it is developed. When an EFL curriculum does not successfully fulfill its main responsibility of teaching a foreign language and its beneficiaries do not see it as worthy of their time and efforts, even its best cultural qualities cannot keep its consumers loyal to it and they will surely turn away from it. The results of this study clearly demonstrated the parental concern for the technical quality of the local curricula which they mentioned as a precondition for preferring the local curriculum to the foreign ones. Moreover, it must be borne in mind that the exclusions should not become exaggerated so that the locally ELT materials become void of the necessary doses of compatible foreign cultures.

\subsection{Implications for forming a regional ELT material association}

While the internationally-marketed ELT materials are by their very nature too general to be capable of responding to the differential needs of the learners with diverse cultural and ideological backgrounds, the locally designed materials suffer from such diametrically opposite shortcomings as being too specific to be of interest to more than one group. A trade-off between these two extremes can be the regionally-developed ELT curricula which have the best of both worlds. They can be both cost effective and capable of taking care of the cultural concerns of their member nations.

\subsection{Implications for Further Research}

Similar studies can be done in countries with a similar concern to find out the nature of the education officials' and parents' attitude towards the western culture when it comes to EFL curriculum development. The more ELT experts invest in the study of the nature of cultural resistance, the more it can lead to a sustainable model of resistance in which professional qualities of ELT programs are not sacrificed by unskillful or exaggerated resistance. Equally worthwhile is the survey of the students and ELT teachers' opinion in this regard.

\section{References}

Cooke, D. (1988) Ties that constrict: English as a Trojan Horse. In A. Cumming, et al, (eds.), Awareness (Ontario: TESL), pp. 56-62.

Hyde, M. (1994) The teaching of English in Morocco: the place of culture. ELT Journal 48(4). Oxford University Press.

Kachru, B.B. (1985). Standards, codification and sociolinguistic realism: The English language in the outer circle. In R. Quirk and H. Widdowson (Eds.), English in the world: Teaching and learning the language and literatures (11-30). Cambridge: Cambridge University Press.

Kubota, R.(1998) Ideologies of English in Japan. World Englishes, 17(3), 295-307

McKay, S. (2002) Teaching English as an International Language: the Chilean context.ELT journal, Vol. 57(2). Oxford University Press.

Modiano, M. (2004) Monoculturalization and language dissemination. Journal of Language, Identity, and Education. 3(3), pp. 215-227

Modiano M. (2009) EIL, Native-speakerism and the Failure of European ELT. In F. Sharifian (Ed.), English as an International Language: Perspectives and Pedagogical Issues. Bristol: Multilingual Matters.

Neustupný, J.V. and Nekvapil, J. (2003): Language management in the Czech Republic. Current Issues in Language Planning 4, 181-366 [reprinted in Baldauf, R.B./Kaplan, R., B. (eds.), Language Planning and Policy in Europe, Vol. 2: The Czech Republic, The European Union and Northen Ireland. Clevedon/Buffalo/Toronto: Multilingual Matters, 2006, pp. 16-201]

Phillipson, R. (1992) Linguistic imperialism. Oxford: Oxford University Press.

Rajagopalan, K. (2004). The Concept of "World English" and its Implications for ELT. ELT Journal 58/2, pp.111-117.

Randal Holmes's (2003) Carrying a Baby in the Back: Teaching with an Awareness of the Cultural Construction of Language, in Byram, M and Peter Grundy (eds.) Context and Culture in Language Teaching and Learning. (pp.18-31) Multilingual Matters Ltd

Richards, J.C. (2003) Current trends in teaching listening and speaking. Transcript of JALT National Conference, Shizuoka, November 22-24, 2003. Tokyo: OUP

Richards JC. (2002). 30 Years of TEFL/TESL: A Personal Reflection [On-line article]. The Regional Language Centre (RELC). Retrieved January 2010 from http://www.professorjackrichards.com/pdfs/30-years-of-TEFL.pdf [Consulted: April 26, 2008]. 
Shafi, M. (1983). “Teaching of English as a Foreign Language: The Islamic Approach.” Muslim Education Quarterly 1(1), pp. 33-41.

Sharifian, F. (ed.) (2009). English as an International Language: Perspectives and pedagogical issues. Clevedon, UK: Multilingual Matters

Table 1. Results of Chi-square goodness of fit test showing parents' overall attitude

\begin{tabular}{|c|c|c|c|c|c|c|c|}
\hline Attitude & Observed $\mathrm{N}$ & Expected N & Residual & Chi square & $\mathrm{df}$ & Sig & Level of significance \\
\hline Approval & $1007(\% 19.71)$ & 1703 & -696.0 & \multirow[t]{3}{*}{4407.038} & \multirow[t]{3}{*}{2} & \multirow[t]{3}{*}{.000} & \multirow[t]{3}{*}{.05} \\
\hline Neutrality & $210(\% 4.11)$ & 1703 & -1493.0 & & & & \\
\hline Resistance & $3892(\% 76.18)$ & 1703 & 2189.0 & & & & \\
\hline
\end{tabular}

Table 2.A component - by - component analysis of parents' attitude

\begin{tabular}{|c|c|c|c|c|c|}
\hline \multirow{2}{*}{ Components } & \multicolumn{3}{|c|}{ Attitude } & \multirow{2}{*}{ Chi square } & \multirow{2}{*}{ Expected Frequency } \\
\cline { 2 - 4 } & Approval & Neutrality & Resistance & & 655 \\
\hline Component 1 & $362(\% 18.42)$ & $67(\% 3.42)$ & $1536(\% 78.16)$ & $1843.899^{\text {a }}$ & 786 \\
\hline Component 2 & $445(\% 18.87)$ & $88(\% 3.73)$ & $1825(\% 77.39)$ & $2141.229^{\text {a }}$ & 262 \\
\hline Component 3 & $200(\% 25.47)$ & $55(\% 7)$ & $531(\% 67.51)$ & $454.405^{\text {a }}$ & \\
\hline
\end{tabular}

For all the three components Sig. $=.000$ and $\mathrm{df}=2$

Table 3.Results of Kruskal-Wallis Test for the effect of income

\begin{tabular}{|c|c|c|c|c|c|}
\hline \multicolumn{3}{|c|}{ Ranks } & \multicolumn{3}{|c|}{ Test Statistics $^{\mathrm{a}, \mathrm{b}}$} \\
\hline Respondents' Income level & $\mathrm{N}$ & Mean Rank & Chi-Square & $\mathrm{df}$ & Sig. \\
\hline Below 700000 Tomans & 166 & 220.95 & \multirow{4}{*}{20.920} & \multirow{4}{*}{2} & \multirow{4}{*}{.000} \\
\hline Between 700000 and 1500000 & 168 & 192.22 & & & \\
\hline Between 1500000 and 3000000 & 59 & 143.21 & & & \\
\hline Total & 393 & & & & \\
\hline
\end{tabular}

a.Kruskal Wallis Test

b. Grouping Variable: Respondents' Income level

Table 4.Results of Kruskal Wallis Test showing the effect of education on parents' attitude

\begin{tabular}{|c|c|c|c|c|c|}
\hline \multicolumn{3}{|l|}{ Ranks } & \multicolumn{3}{|c|}{ Test Statistics ${ }^{\mathrm{a}, \mathrm{b}}$} \\
\hline Respondents' Level of education & $\mathrm{N}$ & $\begin{array}{l}\text { Mean } \\
\text { Rank }\end{array}$ & Chi-Square & $\mathrm{df}$ & Sig. \\
\hline Up to high school diploma & 141 & 208.45 & \multirow{4}{*}{10.281} & \multirow{4}{*}{2} & \multirow{4}{*}{.006} \\
\hline Associated diploma and Bachelor's degree & 179 & 203.55 & & & \\
\hline Master degree and phd & 73 & 158.82 & & & \\
\hline Total & 393 & & & & \\
\hline
\end{tabular}
a. Kruskal Wallis Test
b. Grouping Variable: Level of education

Table 5.Results of Kruskal Wallis for the effect of age on parents' attitude

\begin{tabular}{|l|c|c|c|c|c|}
\hline \multicolumn{2}{|c|}{ Ranks } & \multicolumn{3}{c|}{ Test Statistics ${ }^{\mathrm{a}, \mathrm{b}}$} \\
\cline { 1 - 3 } Respondents' age & $\mathrm{N}$ & Mean Rank & Chi-Square & df & \\
\cline { 1 - 2 } in their 30s & 119 & 206.00 & & & \multirow{2}{*}{13.436} \\
in their 40s & 217 & 205.46 & 2 & .001 \\
\hline in their 50s & 57 & 146.03 & & \\
\hline Total & 393 & & & \\
\hline
\end{tabular}
a. Kruskal Wallis Test
b. Grouping Variable: Respondents' age

Table 6.Results of Mann-Whitney Test for the role of gender in parents' level of resistance

\begin{tabular}{|l|c|c|c|c|c|}
\hline \multicolumn{4}{|c|}{ Ranks } & \multicolumn{2}{c|}{ Test Statistics $^{\mathrm{a}}$} \\
\cline { 1 - 4 } Respondents' gender & $\mathrm{N}$ & Mean Rank & Sum of Ranks & Mann-Whitney U & Sig. (2-tailed) \\
\cline { 1 - 2 } Male & 224 & 199.68 & 44727.50 & \multirow{2}{*}{18328.500} & .591 \\
\cline { 1 - 2 } female & 169 & 193.45 & 32693.50 & & \\
\hline Total & & & & \\
\hline
\end{tabular}

a. Grouping Variable: Respondents' gender 
Appendix A

\begin{tabular}{|l} 
Iranian Parents' Cultural Resistance Questionnaire \\
\hline $\begin{array}{c}\text { Respected sir/madam, } \\
\text { This questionnaire has been designed to survey your attitude towards your children's exposure to the }\end{array}$ \\
incompatible aspects of the western culture and their possible adoption of a western lifestyle. We hope your careful \\
responses will contribute to the success of this survey which aims at the improvement of English teaching in Iran. It is \\
worth mentioning that this questionnaire is anonymous and you are honestly assured that your responses will be kept \\
completely confidential. To save your precious time, a separate participation consent form is not distributed and returning \\
the completed questionnaire is taken as a sign of your consent to participate in this study.
\end{tabular}

\section{Part 1: Attitude Questions}

INSTRUCTIONS: Please underline the appropriate choice in each item to show your reaction to each of the following thirteen questions.

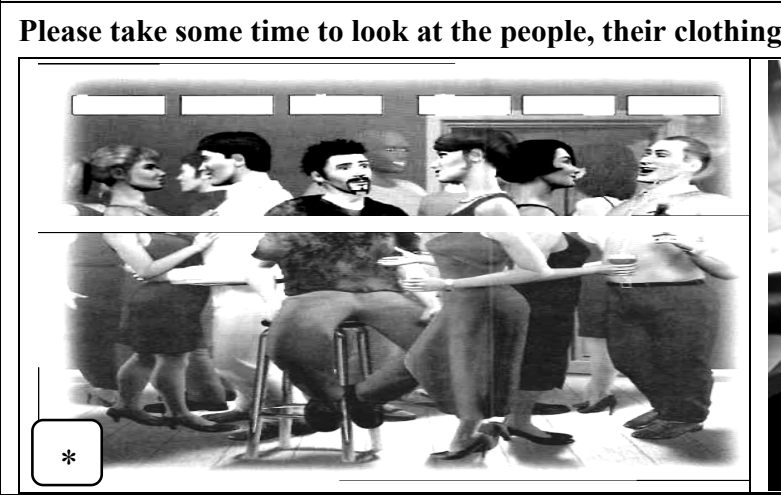

1. To what extent do you approve of your children's participation in such parties?

$\begin{array}{lllllll}\text { Very strongly agree } & \text { Strongly agree } & \text { Agree } & \text { No idea } & \text { Disagree } & \text { Strongly disagree } & \text { Very }\end{array}$
strongly disagree

2. Do you think your child's exposure to the textual and pictorial description of such scenes can negatively affect his / her ideal upbringing?

Absolutely not No, I don't think so No not much I am undecided Yes, to some extent Yes, I think so Yes, absolutely

3. Will you be concerned if your child's English textbooks contain textual and pictorial description of such concepts as cohabitation and mixed student dorm rooms?
Absolutely not
No, I don't think so No not much
I am undecided
Yes, to some extent Yes, I think so Yes, absolutely

4. Are you particular about the cultural appropriateness of the content of the English textbooks your child studies, the instructional movies s/he watches, and the internet sites s/he surfs?
Absolutely not
No, I don't think so
No not much I am undecided
Yes, to some extent
Yes, I think so

Yes, absolutely

5. Do you really feel sad if your child goes to a western style mixed-gender dance party?

Absolutely not No, I don't No, not much I am undecided $\quad$ Yes, to some extent Yes, I think I do

Yes, absolutely

6. To what extent do you agree with this sentence? "Aspects of western lifestyle included in the imported ELT instructional materials can gradually interest the Iranian students in the western ways of life."

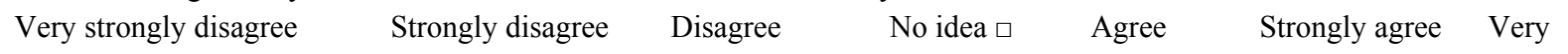
strongly agree

7. If you happen to receive satellite TV channels at home, will you block some channels because you think your children should not be exposed to their contents?
No, not at all
Not, I think so
I am not sure I will
I am undecided
Perhaps I will
Yes, I think so

Yes, I sue will

8. Do you approve the ministry of education's concern that English textbooks used in Iran must be free from the manifestations of the incompatible western culture?

No, not at all Not, I don't No, not much I am undecided Yes, to some extent Yes, to a great extent 


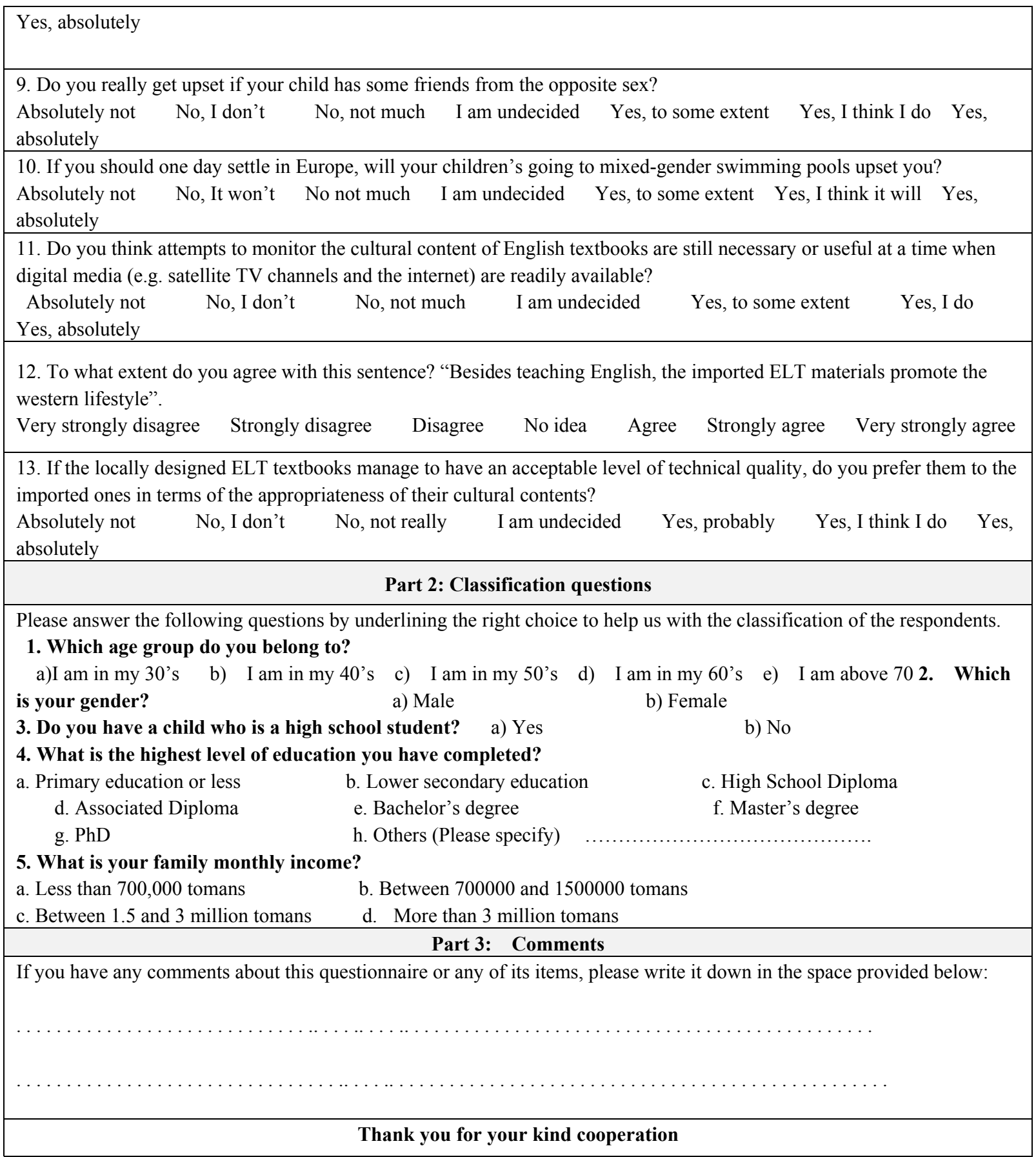

*The picture on the left was taken from New Headway English Course by Liz and John Soars,(2000) Oxford University Press. The second one was taken from www.google.co.in/images. 